\title{
Key to the Paraplatyptilia species of eastern Canada with description of a new species (Lepidoptera: Pterophoridae)
}

\author{
Bernard Landry 1 \\ Muséum d'histoire naturelle, Route de Malagnou 1, C.P. 6434, CH-1211 Genève 6, Switzerland
}

Cees Gielis

Mr. Haafkensstraat 36, 4128 CJ Lexmond, the Netherlands

\begin{abstract}
Paraplatyptilia atlantica sp. nov. is described as new from northwestern Newfoundland and the Gaspé Peninsula, Quebec, Canada. A key to the four species of Paraplatyptilia Bigot and Picard known to occur in eastern Canada (east of Manitoba) is provided.
\end{abstract}

Résumé-Les auteurs décrivent Paraplatyptilia atlantica sp. nov. du nord-ouest de Terre-Neuve et de la péninsule gaspésienne, Québec, Canada. Ils fournissent un tableau de détermination des quatre espèces de Paraplatyptilia Bigot et Picard retrouvées jusqu'à maintenant au Canada à l'est du Manitoba.

\section{Introduction}

The genus Paraplatyptilia Bigot and Picard (Lepidoptera: Pterophoridae) currently includes 31 described species, 19 of which are distributed in the Nearctic region (mostly the western part) and 11 in the Palaearctic region, with 1 species known from the Neotropical region (Gielis 2003). Along with the new species described below, there are now 4 species of Paraplatyptilia in Canada east of Manitoba. Three more species, P. auriga (Barnes and Lindsey 1921), described from New Jersey, and two undescribed species (C.G., unpublished data), are known to occur in eastern North America south of Canada. The recorded host plants of Paraplatyptilia mostly belong to genera in the Orobanchaceae (Aureolaria Raf., Castilleja Mutis ex L.f., Pedicularis L.) and Plantaginaceae (Penstemon Schmidel) (Matthews and Lott 2005).

The adults of Paraplatyptilia spp. are characterized by the presence, in most species, of a tuft of dark-brown scales subapically on the inner margin of the third lobe of the hind wing, the large and apically spatulate uncus in the male genitalia, and the short, tubelike, and dextrally situated antrum in the female genitalia. Although the last character also occurs in some species of Stenoptilodes Zimmerman, the uncus is apically slender and often short in that genus.

The first author (B.L.) recorded a new species of Paraplatyptilia collected in Quebec on Mount Albert in the Parc national de la Gaspésie (Landry 1987), but the description was not published because the few known specimens were in poor condition and because the possibility that the species was already described from the Arctic or the Rocky Mountains was not fully investigated. Then the first author started to collaborate on Pterophoridae projects with the second author, C.G., who found a small series of Paraplatyptilia females in the Helsinki Museum that had been collected in Newfoundland. Our mutual investigations of both series of specimens led us to conclude that they represented the same species, and our accumulated knowledge of the Holarctic Pterophoridae fauna confirmed that the species was new to science.

The purpose of this paper is to describe and illustrate this new taxon in the hope that more material will be found and that its biology will be investigated. We also provide a key to all species of Paraplatyptilia in eastern Canada (east of Manitoba) to allow for easier determinations.

Received 20 April 2007. Accepted 7 September 2007.

${ }^{1}$ Corresponding author (e-mail: bernard.landry@ville-ge.ch). 
Figs. 1, 2. Wings of paratypes of Paraplatyptilia atlantica sp. nov.: 1, Doctors Brook female (length of forewing $9.47 \mathrm{~mm}$ ); 2, Mount Albert male (length of forewing $9.33 \mathrm{~mm}$ ).

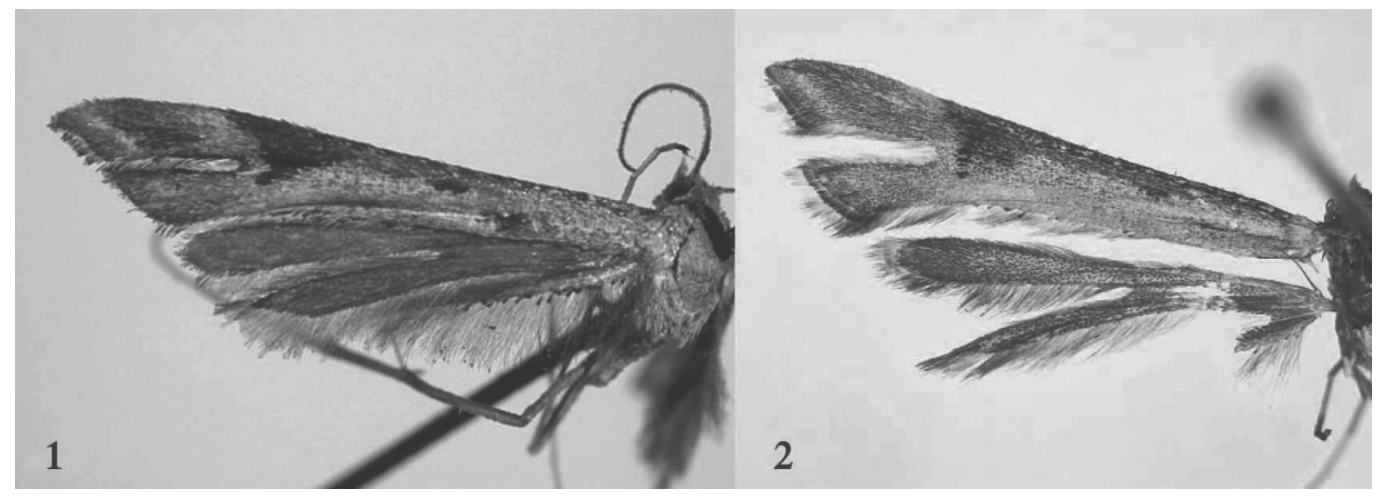

\section{Material and methods}

The specimens forming the basis for this study are deposited in the Lyman Entomological Museum, McGill University, Ste-Anne-de-Bellevue, Quebec, Canada (LEMQ), the Zoological Museum of the University of Helsinki, Finland
$(\mathrm{FMNH})$, and the private collection of C.G. (CGC). Except for Figure 1 the illustrations were made with AutoMontage ${ }^{\circledR}$. The genitalia were stained with Orange $\mathrm{G}$ and Chlorazol Black E except for those of one female (Fig. 7), which were stained with Chlorazol Black E only. Terminology follows Gielis (1993) and Landry (1987).

\section{Key to Paraplatyptilia species of eastern Canada}

1. Ground colour of forewing ochre . . . . . . . . . . . . . . . . . . . . . P. carolina (Kearfott)

1'. Ground colour of forewing greyish brown or grey . . . . . . . . . . . . . . . . . . . . . . 2

2. Forewing with conspicuous dark-brown oblique dash in middle of first lobe, margined with equally oblique white dashes; restricted to north of latitude $60^{\circ} \mathrm{N}$. . . . . . . . . . P petrodactyla (Walker)

$2^{\prime}$. Forewing with first lobe medially without conspicuous dark-brown oblique dash margined with equally oblique white dashes; restricted to south of latitude $55^{\circ} \mathrm{N}$. . . . . . . . . . . . . . . . . . . . . . 3

3. Wingspan more than $20 \mathrm{~mm}$; inner margin of third hind-wing lobe with narrow tuft of dark-brown scales subapically; male genitalia with basal section of sacculus strongly produced ventrally, broadly rounded, and long compared with indistinct distal section; cucullus with angular margin; female genitalia with medial margin of antrum convex, similar in shape to left medial margin of sternite; lamina postvaginalis forming large, rounded plate with low apical depression . . . . . . . . . . . . P. edwardsii (Fish)

3'. Wingspan usually less than $20 \mathrm{~mm}$; inner margin of third hind-wing lobe apparently always without tuft of dark-brown scales subapically; male genitalia (Fig. 3) with basal section of sacculus almost as produced as distal section and only slightly longer; cucullus margin rounded; female genitalia (Figs. 6-8) with medial margin of antrum convex or straight, distinctly asymmetric from left medial margin of sternite; lamina postvaginalis narrow . . . . . . . . . . . . . . . . . . . . P. atlantica sp. nov.

\section{Species description}

\section{Paraplatyptilia atlantica sp. nov. Figs. 1-8}

\section{Type material}

Holotype o : (1) "Doctors Brook I NW Newfoundland | 31.VII.1949 | H. Krogerus"; (2) "4824"; (3) "HOLOTYPE I Paraplatyptilia । atlantica | Landry and Gielis"; (4) "[genitalia slide] BL 1647 of". Lacking the left foreleg and the right midleg beyond the trochanter and half of the right antenna; otherwise in good condition although unspread. Deposited in FMNH. Paratypes: $40^{x} 0^{x}, 5$ 우우: 3 우우, same data as holotype (2 dissected, genitalia slide Nos. CG 3959, 3960 in FMNH and CGC; undissected

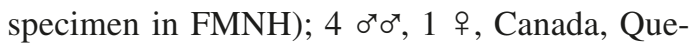
bec, M[oun]t. Albert, Gaspé Prov[incial]. Park, 3500 ft, 17-21.vii.1970 (C.Y.W. Boyle), genitalia slide Nos. LEMQ $27 \sigma^{\star}, 152$ 우, $153 \sigma^{\star}$, BL $1644 \sigma^{x}$ (LEMQ); 1 ㅇ, Canada, Quebec, Mt. Albert, N[orth]. Slope, 16.viii.1971 (C. Boyle, G. Ladd), genitalia slide No. BL 1645 우 (LEMQ). 
Figs. 3-5. Male genitalia of Paraplatyptilia atlantica sp. nov. from slide BL 1644 (LEMQ): 3, genitalia without phallus (length of right valva $0.89 \mathrm{~mm}$ ); 4, anellus, sacculus, harpe, and vinculum; 5, phallus.

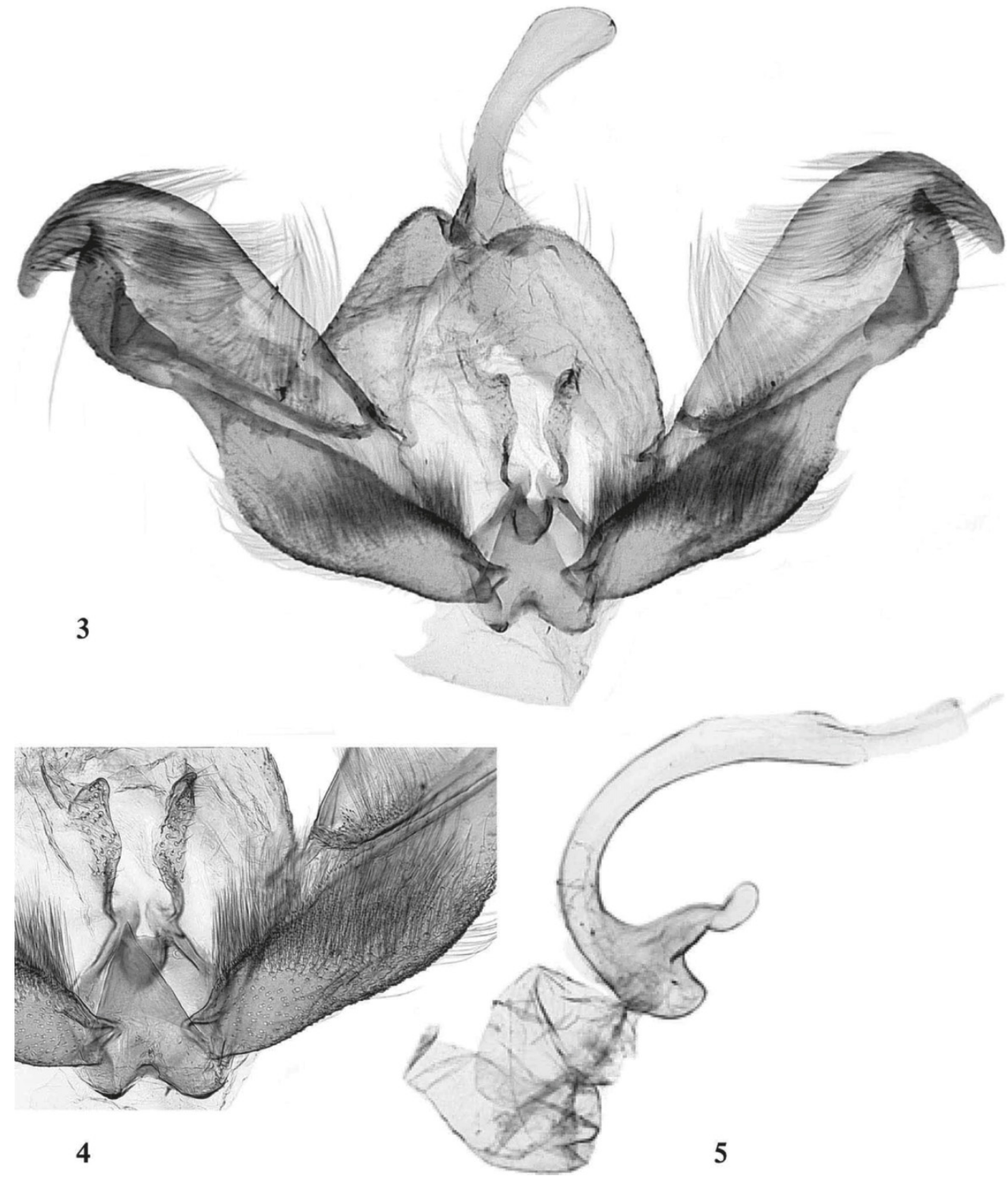

\section{Diagnosis}

This is a small greyish brown species with a wingspan $20 \mathrm{~mm}$ or less, with a distinct dark-brown triangle on the forewing before the cleft, and no dark-brown scale tuft on the inner margin of the third hind-wing lobe. The female genitalia are characterized by a narrow lamina postvaginalis with well-separated short lateral lobes. The male genitalia are characterized by the uncus curved ventrally at a right angle from $1 / 3$, the ventral margin of the sacculus with well-demarcated, rounded, and produced basal and distal sections, the cucullus with a rounded margin and narrowly rounded apex, and the phallus with a poorly differentiated apex.

\section{Description}

Habitus (Figs. 1, 2). Head appressedly scaled, greyish brown and ochreous beige and brown on frons laterally, with white laterally and behind eye; frons slightly produced by about $2 / 5$ eye diameter, in shape a broad, apically rounded triangle. Labial 
Figs. 6-8. Female genitalia of Paraplatyptilia atlantica sp. nov.: 6, whole genitalia of holotype (length of corpus bursae $1.15 \mathrm{~mm}$ ); 7, antrum area of Doctors Brook paratype (slide CG 3960; CGC); 8, antrum area of Mount Albert paratype (slide BL 1645; LEMQ).

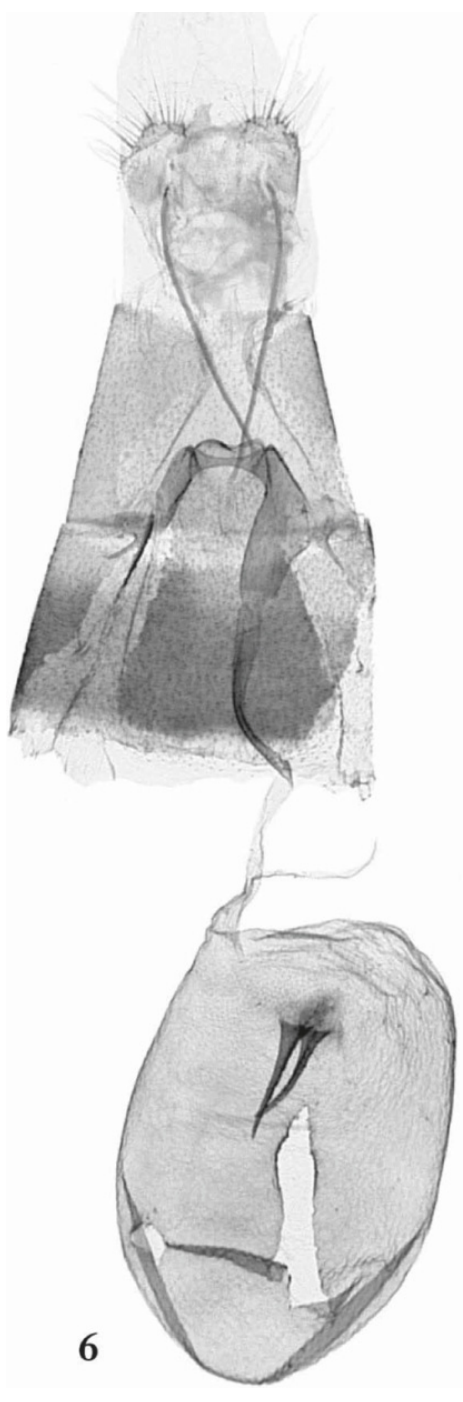

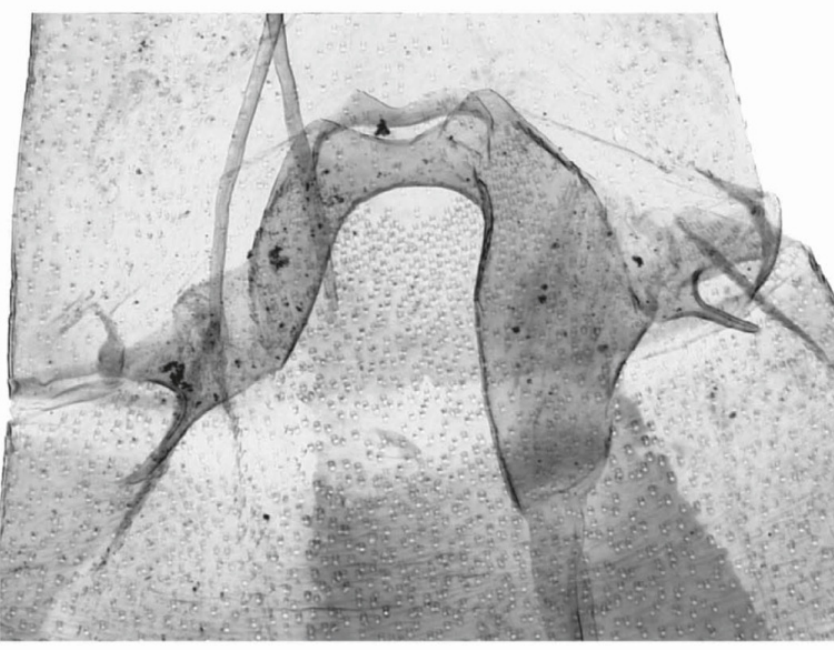

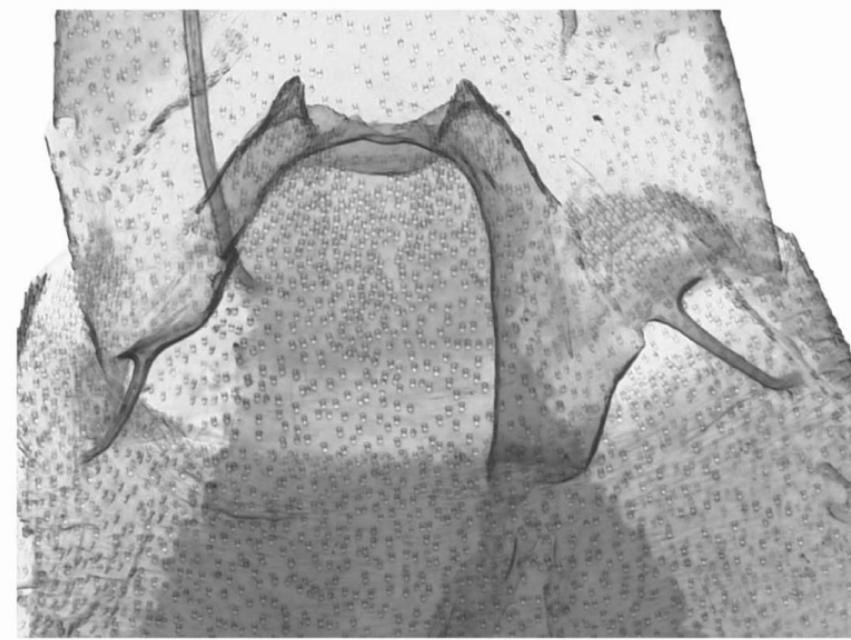

palpus reaching beyond eye by length of eye diameter; white ventrally and dorsally on first palpomere and dorsally at tip, elsewhere beige to brown; second palpomere with distal scales ventrally reaching tip of third palpomere, dorsally forming short tuft. Antenna with scape, pedicel, and first flagellomeres white ventrally, brown dorsally; rest of flagellum with greyish brown and white scales. Thorax mostly pale beige and white, with brown at base of tegula, slightly ochreous on mesothorax. Foreleg coxa medially brown to dark brown toward tip, with thin white longitudinal line at base, white along ventral edge, laterally mostly ochreous beige with white along dorsal edge; femur medially brown, laterally white, with scattered ochreous beige scales; tibia medially brown with few white scales, laterally white; tarsi greyish brown medially, laterally white to pale grey toward last tarsomere. Midleg coxa ochreous beige and white; femur laterally brown with scattered ochreous beige scales, medially white, with ochreous beige stripe; tibia laterally brown, with thin white line, medially white; tarsi as in foreleg. Hind-leg coxa pale ochreous beige and white; femur ochreous beige laterally, white medially; tibia and tarsi pale greyish brown laterally, paler medially; tibia with two pairs of spurs with proximal pair longer than distal pair and with medial spurs 
slightly longer than lateral ones. Wingspan 17.1-20.4 mm (holotype $17.1 \mathrm{~mm}$ ). Forewing ground colour pale grey-brown (Figs. 1, 2) with scales white, beige, and brown; dark-brown markings as small (8-10 scales long) discal spot at $1 / 3$, wider spot close to inner margin at $1 / 5-1 / 4$, costal triangle before base of cleft, with arched distal margin, diagonal spot in middle of first lobe, dense scaling along costa; white scaling mostly before cleft below costa, as faint diagonal band in first lobe subapically, and speckled in costa; cleft at 7/10; fringe brown with white spots below apex and on inner margin of second lobe, beige on inner margin of first lobe; underside pale brown with dark brown before cleft and white in both lobes, but especially as diagonal bar subapically in first lobe. Hind wing brown with paler greyish brown fringe; with row of dark-brown scales along inner margin of third lobe from base to $3 / 5$; underside mostly pale greyish brown in first two lobes, with white subterminal transverse line in first lobe, mostly white on third lobe; specialized (venous) scales orange-brown, in two rows, with costal row longer. Abdomen dorsally with first segment white with pale beige in middle, with pale greyish brown median band from base of segment II to apex, white elsewhere except for pair of dark-brown spots at apex of segments III-VI laterally; beige ventrally with three narrow brown lines and two white ones in between.

Male genitalia $(n=2)$ (Figs. 3-5). Uncus wide, enlarged from $2 / 3$, slightly hooked apically; in side view forming right angle from $1 / 3$. Tegumen in side view more or less rectangular; with narrowly rounded dorsal lobes. Valva with basal section of sacculus set with short spines on costal edge near base of harpe, distinctly produced and rounded ventrally, with broad concavity separating it from shorter, rounded distal section; harpe set with long setae subbasally, with base upturned and set with short, strong spines; cucullus evenly rounded, with apex rounded. Anellus arms slightly enlarging at $1 / 3$ and $2 / 3$, narrowly rounded apically. Vinculum triangular, pointed, reaching base of anellus arms. Phallus long, narrow, only slightly enlarged apically; dorsal margin at apex slightly more thickly sclerotized than subapically and set with few small crescent-shaped incisions; ventral margin apically with few very small spines; coecum penis short; ventral process $\mathrm{S}$-shaped, at right angle to coecum penis.

Female genitalia $(n=5)$ (Figs. 6-8). Papillae anales small and rounded. Apophyses posteriores slender, 3-4 times length of papillae anales, extending to antrum. Ostium dextral, oblique. Antrum 1.75-1.88 times longer than wide at widest point, with medial margin slightly convex or straight. Lamina antevaginalis forming median low, broadly rounded depression, with lateral lobes short and smoothly rounded or adorned with large triangular projection bearing scale sockets. Lamina postvaginalis narrow, apical margin with narrow medial depression and low, rounded or triangular lateral lobes (sometimes asymmetric as in Figure 7). Ductus bursae slender, with elongate sclerite 1/2 length of ductus, nearly touching antrum. Corpus bursae slightly elongate, with spicules around bases of signa and sometimes to distal end; signa about 1/5-1/4 length of corpus bursae, slightly curved, with more or less serrated medial margin.

\section{Ecology}

The moth flies in July and August and at up to about $1100 \mathrm{~m}(3500 \mathrm{ft})$ on Mount Albert. The host plant is unknown.

\section{Distribution}

CANADA. Newfoundland and Labrador: Northern Peninsula of Newfoundland. Quebec: Gaspé Peninsula, Mount Albert.

\section{Etymology}

The new name refers to the area of occurrence, Newfoundland and Labrador being one of the Canadian provinces collectively known as Atlantic Canada.

\section{Remarks}

In colouration, five out of the six Mount Albert specimens have less conspicuous dark-brown markings (Fig. 2) and the abdomen of one is darker, greyish brown, and without marked lines ventrally. The two sets of male genitalia available for comparison, both from Mount Albert, show no discernible variation. The female genitalia differ in the shape of the antrum, those of Mount Albert females having the medial margin straight instead of slightly convex (Figs. 7, 8), in the shape of the lateral lobes of the laminae ante- and post-vaginalis, which can be smoothly rounded or more triangular with scale sockets, the length of the anterior apophyses, which are slightly longer in the Mount Albert specimens, and the overall length of segments VII and VIII, which is slightly greater in the Newfoundland specimens. We believe that these variations are intraspecific, and this could be ascertained if more material was 
available for study. The type locality, Doctors Brook, is a river south of Barr'd Harbour at $50^{\circ} 47^{\prime} 53^{\prime \prime} \mathrm{N}, 57^{\circ} 04^{\prime} 29^{\prime \prime} \mathrm{W}$; it is a site of conservation interest for its flora (see http://www. digitalnaturalhistory.com). We assume that the collecting locality was low in elevation, but the collector's notes, if there ever were any, could not be found at FMNH (L. Kaila, personal communication to B.L.), and Krogerus (1954) did not describe the locality. Culminating at $1154 \mathrm{~m}$, Mount Albert is part of the Chic-Choc mountains. It is characterized by poor serpentine soils, which support a specialized vegetation that includes a number of endemic species, but so far, only one insect (Melanoplus gaspesiensis Vickery (Orthoptera: Acrididae)) has been reported to be endemic to the mountain (Lesage and Paquin 2000). The collecting locality of $P$. atlantica on Mount Albert was at or near the summit, but no more is known concerning this collecting event. Certainly the range of this species is incompletely known, but the most likely pattern of distribution is that of the zones of endemism in northeastern North America, i.e., the point of land at the northeast of Ungava Bay, the northern part of the west coast of Newfoundland (including Doctors Brook), and the region comprising the Mingan Islands, Anticosti Island, and part of the Gaspé Peninsula (including the Chic-Choc mountains) (Argus 1977; Lesage and Paquin 2000).

In an effort to obtain more specimens of $P$. atlantica we contacted curator Alma Solis (United States National Museum (USNM), Washington, District of Columbia) and collector Michael A. Roberts from Maine. In Washington, Reed Watkins thoroughly went through the USNM Pterophoridae collection, including specimens collected by A.E. Brower from Maine, but neither he nor Mr. Roberts turned up any additional specimens.

The genitalia preparations made by B.L. in 1987 from three specimens of this species, bearing numbers LEM 27, 152, and 153, could not be found at LEMQ. However, the male and female genitalia on two of these slides were photographed and figured in Landry (1987). These illustrations are used here in the description and in giving the number of genitalia preparations examined.

A female was chosen as the holotype because it was the most complete specimen available, and the female genitalia in this genus often have as many, and sometimes more, diagnostic characters.

\section{Acknowledgments}

We thank curators Lauri Kaila (FMNH) and Stéphanie Boucher (LEMQ) for the loan of specimens in their care, Lauri Kaila, Louis Marcotte, Michael A. Roberts, Alma Solis, and Reed Watkins for providing useful information, Terry Wheeler and three anonymous reviewers for their useful comments, and Florence Marteau for producing the plates.

\section{References}

Argus, G.W. 1977. The conservation of rare and endangered plants. In Canada's threatened species and habitats. Edited by T. Mosquin and C. Suchal. Canadian Nature Federation, Ottawa, Ontario. pp. 139-143.

Barnes, W., and Lindsey, A.W. 1921 The Pterophoridae of America, north of Mexico. Contributions to the Natural History of the Lepidoptera of North America, 4: 281-484.

Gielis, C. 1993. Generic revision of the superfamily Pterophoroidea (Lepidoptera). Zoologische Verhandelingen (Leiden), 290: 1-139.

Gielis, C. 2003. Pterophoroidea and Alucitoidea (Lepidoptera). In World catalogue of insects. Vol. 4. Edited by H. van der Wolf. Apollo Books, Stenstrup, Denmark.

Krogerus, H. 1954. Investigations on the Lepidoptera of Newfoundland. I. Macrolepidoptera. Acta Zoologica Fennica, 82: 1-80.

Landry, B. 1987. A synopsis of the plume-moths of the subfamily Platyptiliinae (Lepidoptera: Pterophoridae) of eastern Canada. M.Sc. thesis, McGill University, Montréal, Quebec.

Lesage, L., and Paquin, P. 2000. Historique, géographie physique et biogéographie du Parc de conservation de la Gaspésie, Québec. Proceedings of the Entomological Society of Ontario, 131: 17-66.

Matthews, D.L., and Lott, T.A. 2005. Larval hostplants of the Pterophoridae (Lepidoptera: Pterophoroidea). Memoirs of the American Entomological Institute, 76: 1-324. 